\title{
Resistencia e involución social en las comunidades de la Edad del Bronce del sureste de la Península Ibérica
}

\author{
Resistance and social involution in the Bronze Age communities of southeastern Iberia
}

\author{
Gonzalo Aranda Jiménez (*)
}

\section{RESUMEN}

Las comunidades argáricas han sido consideradas como la culminación de un largo proceso de creciente complejidad que condujo hacia formas sociales cada vez más asimétricas e identidades más individualizadas. El presente trabajo explora no tanto las causas que desencadenaron este proceso como los fenómenos de resistencia a estas dinámicas sociales y económicas. Si tenemos en cuenta los cambios y continuidades que se produjeron a lo largo de la Edad del Bronce, estos fenómenos deben ser considerados como exitosos. En este sentido, la desaparición de los enterramientos individuales y la generalización de los colectivos, la continuidad en la reutilización de sepulturas megalíticas, la escasa división de funciones y especialización artesanal que caracterizaría al Bronce Tardío y Final o la vuelta a una arquitectura dominada por formas circulares y ovaladas, son algunos de los aspectos que marcarían el cambio hacia formas sociales menos complejas donde primarían la colectividad y las identidades relacionales.

\begin{abstract}
Argaric communities (EBA) have been traditionally explained as the result of a long process of increasing complexity that led to deep social asymmetries and individualized identities. This paper explores not so much what triggered this process as the phenomenon of resistance to this social and economic dynamic. If one considers the cultural changes and continuities that occurred
\end{abstract}

(*) Dpto. de Prehistoria y Arqueología. Universidad de Granada. Campus Cartuja s/n. 18071 Granada. Correo e.: garanda@ugr.es

Recibido: 14-I-2014; aceptado: 13-IV-2014. over the course of the Bronze Age as a whole, this resistance should be considered successful. In this sense, the disappearance of individual burials, the continued reuse of collective megalithic graves, the simpler division of labour and craft specialization that characterized the Late Bronze Age, and the return to an architecture dominated by circular and oval shapes are some of the aspects that reflect less complex societies and an increased emphasis on community organization and collective identities.

Palabras clave: Edad del Bronce; Sureste de la Península Ibérica; Complejidad social; Resistencia; Individualización; Identidad relacional; Involución social; Prácticas funerarias; Urbanismo; Metalurgia.

Key words: Bronze Age; Southeast of Iberia; Social Complexity; Resistance; Individualization; Collective Identity; Social Involution; Funerary Practices; Urbanism; Metallurgy.

\section{INTRODUCCIÓN}

El análisis del origen de la complejidad social es sin duda uno de los grandes temas de investigación de la Prehistoria Reciente y probablemente una de las más importantes aportaciones de nuestra disciplina a la sociedad actual. ¿Por qué las comunidades abandonan relaciones sociales y económicas esencialmente igualitarias?, ¿cuáles son las causas que desencadenan el proceso de jerarquización social? o ¿qué conduce a determinados sectores sociales a aceptar una situación de desventaja social y económica? son algunos de los interrogantes que ha generado una enorme 
bibliografía no sólo arqueológica o antropológica sino en las humanidades en general. A nadie se le escapa la enorme actualidad de estas preguntas. De cómo encaremos su análisis y del tipo de respuesta que seamos capaces de proporcionar dependerá el que estemos favoreciendo uno u otro tipo de discurso político y de intereses particulares en no pocas ocasiones contrapuestos. Ni las preguntas ni las respuestas son inocentes, muy al contrario están cargadas de importantes implicaciones que dan sentido a nuestro trabajo.

Quizás uno de los elementos comunes en las diferentes aproximaciones al origen y desarrollo de la desigualdad social sea el reconocimiento de que se trata de complejas dinámicas resultado de procesos históricos de largo recorrido. En este sentido, los diferentes modelos de evolución social han destacado tradicionalmente todos aquellos elementos relacionados con el cambio, enfatizándose trayectorias históricas que conducían desde lo simple a lo complejo (Service 1962; Fried 1967; Childe 1936 entre los modelos más conocidos). Los diferentes niveles de complejidad socioeconómica, habitualmente definidos como bandas, tribus, jefaturas y estados, han sido tratados como diferentes etapas de un mismo proceso, al margen de las causas propuestas para su explicación. La Península Ibérica no ha sido ajena a estos debates, muy especialmente en las últimas décadas. Sirva como ejemplo de este interés la reciente publicación The Prehistory of Iberia. Debating Early Social Stratification and the State (Cruz Berrocal et al. 2013), donde un nutrido grupo de investigadores e investigadoras aborda el debate sobre el origen de la desigualdad social y la aparición del estado.

En este contexto, el objetivo del presente trabajo no es tanto el análisis de las dinámicas sociales que conducen a formas asimétricas de organización social como el estudio de los fenómenos de resistencia a aquellos procesos históricos que tratan de establecer y consolidar determinadas desigualdades sociales. La investigación de estos procesos ha tenido una exigua relevancia en el análisis de las sociedades prehistóricas a pesar de su importancia en la teoría social y política de autores clásicos como Weber o Gramsci o en el desarrollo de la teoría crítica de la Escuela de Frankfurt (Miller et al. 1989). En los últimos años, sin embargo, el estudio de estos fenómenos ha comenzado a adquirir una cierta relevancia gracias especialmente al desarrollo de la denominada como Arqueología Postcolonial (Lydon y Rizvi 2010). La reivindicación del papel activo de los "colonizados" ha estimulado el estudio de complejos procesos donde la emulación, la hibridación, la dominación y la resistencia han pasado a ocupar un lugar preeminente en las nuevas narrativas (Gosden 1999, 2004; Van Dommelen 2008, 2011).

Especialmente la resistencia puede ser considerada un elemento consustancial a todas la sociedades humanas. Alterar o modificar las condiciones de vida siempre implica un riesgo ya que sólo manteniendo los sistemas culturales conocidos se tiene confianza en una supervivencia exitosa. De esta forma, el rechazo al cambio genera formas pertinaces de resistencia y sociedades muy estables a largo plazo. En realidad, la noción de que los seres humanos tienden a mejorar sus condiciones de vida a través de la innovación tecnológica forma parte del pensamiento ilustrado y no de la realidad de la mayor parte de las sociedades pasadas en las que el cambio no ha sido querido ni deseado (Hernando 2002).

No obstante, la voluntad de mantener determinadas formas culturales no significa inmovilismo, es decir, la resistencia no debe considerarse como la antítesis del cambio, al contrario, la resistencia implica una actitud activa y dinámica en la que el cambio está presente, eso si los cambios se realizan para mantener las formas de vida no para transformarlas (Parcero y Criado 2013). Numerosos ejemplos etnográficos ilustran este principio: "cuando los indios descubrieron la superioridad productiva de las hachas (metálicas) de los hombres blancos, las quisieron, no para producir más en igual tiempo, sino para producir tanto como antes en un tiempo diez veces menor" (Clastres 2010: 208).

La resistencia como principio estructurador de las sociedades humanas adquiere formas diferenciadas dependiendo del grado de complejidad cultural. El desarrollo de sistemas sociales basados en una creciente división de funciones y especialización genera una fragmentación social donde la percepción del cambio comienza a ser considerada de forma diferente dependiendo de cada grupo social y del grado de individualización alcanzado (Hernando 2002, 2012). Las tensiones que provoca en el seno de una comunidad la convivencia de tendencias sociales más conservadoras frente a

Trab. Prehist., 72, N. ${ }^{\circ}$ 1, enero-junio 2015, pp. 126-144, ISSN: 0082-5638 doi: $10.3989 /$ tp. 2015.12147 
otras más transformadoras estimula formas cada vez más elaboradas tanto de resistencia como de imposición de nuevas percepciones de la realidad.

Como recientemente han enfatizado investigadores como James Scott (2003), la institucionalización de la explotación social y económica intensifica los fenómenos de resistencia. En cualquier proceso de jerarquización, las cada vez más elaboradas formas de coerción física e ideológica, que en los casos más avanzados adoptan la forma de ejército e instituciones religiosas, serían un claro ejemplo de los mecanismos de imposición de un nuevo orden social aunque a la vez un reconocimiento indirecto de la importancia que adquieren las prácticas de resistencia. En otras palabras, la necesidad de "persuadir" a la población de la "bondades" del sistema socio-económico evidenciaría las fuertes tensiones sociales existentes entre colectivos favorecedores del cambio frente a aquellos otros grupos partidarios de mantener formas culturales tradicionales. Complejidad social y resistencia pueden ser consideradas las dos caras de una misma moneda. Por tanto, es previsible que situaciones sociales cada vez más desiguales e individualizadas generen prácticas de resistencia igualmente más intensas y elaboradas.

En este contexto, propongo como caso de estudio la Edad del Bronce del sureste de la Península Ibérica, cuyas etapas iniciales han venido siendo consideradas como la culminación de un largo proceso de complejidad social que se inicia a finales del IV milenio cal BC. De la diversidad de trayectorias históricas reconocibles en las diferentes regiones peninsulares, la Prehistoria Reciente del sureste posiblemente sea el ejemplo más claro, al menos el más intensamente investigado, de evolución hacia formas sociales cada vez más asimétricas. Parece, por tanto, un contexto especialmente propicio para el estudio de los fenómenos de resistencia. La aproximación que proponemos supone el análisis del rol de estos fenómenos en el cambio que se produce en la Edad del Bronce con el colapso de las sociedades argáricas, el final de sus elaboradas formas de asimetría social y la aparición de lo que parece ser un proceso de clara involución social hacia formas sociales menos complejas donde primaría la colectividad frente a individualidad.

La argumentación que a continuación desarrollo asume que la evolución social no es lineal y que, por tanto, la complejidad es un fenómeno de "ida y vuelta", donde las trayectorias históricas evolucionan y cambian de múltiples formas, sin un plan predeterminado. Estructuralmente los grupos sociales se mueven entre la tendencia a la división o fragmentación, que crea oportunidades para la desigualdad, y a la resistencia, que trata de inhibir o contrarrestar las dinámicas que favorecen esta división social, manteniendo formulas organizativas mucho más colectivas (Vicent 1998). De cómo en cada momento histórico estas tendencias opuestas se resuelvan dependerá que se produzca la formación de sociedades con diferentes grados de complejidad.

\section{COMPLEJIDAD SOCIAL EN EL SURESTE DE LA PENÍNSULA IBÉRICA}

Los años 1970 trajeron a la Prehistoria española nuevos aires de renovación teórica y metodológica que supusieron el abandono de los modelos de evolución social basados en desplazamientos poblacionales o en influencias procedentes de lugares lejanos. Desde entonces, es en las dinámicas internas de las comunidades asentadas en la península donde se han buscado las razones de los procesos de cambio cultural. Así, las profundas trasformaciones protagonizadas por las comunidades que conocemos como Culturas de Los Millares y de El Argar han sido consideradas como diferentes etapas de un proceso que conducía hacia formas cada vez más jerarquizadas de organización social.

La Edad del Cobre del Sureste de la Península Ibérica (c. 3200-2200 cal BC) supuso el inicio de un proceso de creciente complejidad social caracterizado por la conjunción de varios factores: crecimiento demográfico y concentración poblacional, una adscripción cada vez más intensa de grupos sociales a territorios específicos, asentamientos de grandes dimensiones fuertemente monumentalizados, el desarrollo de la metalurgia del cobre, la intensificación de redes de intercambio regional y suprarregional y complejas prácticas rituales que incluían una gran diversidad en la forma, tamaño y localización de sepulturas megalíticas y cuevas artificiales y naturales.

En términos generales, se asume que estos cambios se producen en una organización social de carácter segmentario donde las relaciones con-

Trab. Prehist., 72, N. ${ }^{\circ}$ 1, enero-junio 2015, pp. 126-144, ISSN: 0082-5638

doi: $10.3989 /$ tp. 2015.12147 
sanguíneas y de parentesco eran el elemento de referencia que estructuraba las diferentes formas de identidad. En este contexto, las dinámicas sociales de III milenio cal BC pondrían constantemente a prueba los principios de solidaridad y reciprocidad inherentes a estas formas organizativas. Efectivamente, las tensiones sociales y la competición entre linajes han sido recurrentemente señaladas como una de las características principales de estas comunidades (Chapman 1981, 2003, 2008; Gilman 1987, 2001, 2013; Castro et al. 1998; Díaz del Río 2004, 2008, 2011). Construcciones monumentales en piedra o las diferencias en la forma, tamaño y ajuares documentados entre sepulturas megalíticas son algunas de las evidencias propuestas para apoyar unas incipientes asimetrías sociales. En cualquier caso, los intentos por consolidar y reproducir estas diferencias toparían constantemente con la oposición a "trabajar para otros" y con la división y fragmentación de la comunidad si fuera necesario. En palabras de P. Clastres (2010: 166) en sociedades no-estatales "a un jefe que quisiera hacer de jefe, se le abandonaría".

Las sociedades calcolíticas experimentarían, de esta forma, una contradicción entre los cambios anteriormente indicados, que ofrecen posibilidades para la diferenciación social, y un orden social basado en el parentesco y en la reciprocidad. Un vistazo a lo que sucede durante la Edad del Bronce en la Península Ibérica confirmaría que la resistencia a "trabajar para otros" fue exitosa. Ciertamente, la fragmentación social, la diversidad de trayectorias y la interrupción en el desarrollo de formas culturales cada vez más complejas parecen ser características habituales en estas comunidades. Esta tendencia general posee, sin embargo, una clara excepción. Se trata de las sociedades del sureste peninsular conocidas como Cultura de El Argar (c. 2200-1550 cal BC), en donde se produjo el fenómeno contrario: una profundización en las desigualdades sociales que aparentemente inhibió los mecanismos de división característicos de las sociedades parentales, creando nuevas estructuras de poder. Pero, ¿por qué el sureste?, ¿cuáles son las causas que estimularon lo que parece un salto cualitativo en las formas de relación social?

Diferentes investigadores han encontrado en la adaptación a la aridez de estas comarcas el elemento diferenciador (Chapman 1977, 1978, 1981; Mathers 1984a, 1984b), aunque sólo An- tonio Gilman $(1976,1981,1987,2001,2013)$ ha presentado una formulación explícita sobre cómo las sociedades prehistóricas fueron capaces de inhibir los mecanismos de resistencia parentales. La inversión en infraestructuras agrícolas (sistemas de irrigación) habría abierto la puerta a los mecanismos de explotación social y económica. La extorsión promovida por determinados líderes sociales sería aceptada por el resto de la población ya que los costes para hacer frente a las demandas de excedentes serían inferiores al abandono de las inversiones realizadas. Otros investigadores han preferido, sin embargo, situar en la especialización metalúrgica la causa principal que transformaría las relaciones sociales en época argárica (Lull 1983; Lull et al. 2009, 2010, 2011).

Estos modelos interpretativos son actualmente objeto de una importante controversia científica. En cualquier caso, parece existir un cierto acuerdo en que el proceso de evolución social iniciado a finales de IV milenio cal BC habría alcanzado en época argárica su "punto culminante", bien con la aparición del Estado como garante de una clara situación de explotación social y económica (Lull y Risch 1995; Arteaga 2001; Contreras y Cámara 2002; Chapman 2003; Lull et al. 2009, 2010; Cámara y Molina 2011), bien con la consolidación de un sistema de jefaturas, socialmente asimétrico pero políticamente mucho más inestable (Gilman 1981, 2001, 2013; Ramos Millán 1981, 2013; Bartelheim 2012). Al margen del debate sobre el grado de jerarquización social y la forma política que adoptan las comunidades argáricas, parece evidente con la documentación disponible que durante este periodo se habría producido un incremento en la complejidad social en comparación con las previas comunidades calcolíticas. Veamos algunos de los elementos centrales que en mi opinión fundamentan este profundo y rápido cambio.

El inicio de El Argar coincidió con el abandono de la mayoría de los asentamientos calcolíticos y la fundación de otros nuevos. La reordenación del poblamiento supuso un elemento distintivo de las sociedades argáricas donde los poblados en altura alcanzan un enorme protagonismo. $\mathrm{Su}$ habitual localización en lugares elevados y el uso frecuente, incluso masivo, de mampostería en sus construcciones enfatizaría su relevante dimensión paisajística. La ocupación de escarpados cerros mediante un urbanismo compacto, donde las edi-

Trab. Prehist., 72, N. ${ }^{\circ}$ 1, enero-junio 2015, pp. 126-144, ISSN: 0082-5638 doi: $10.3989 /$ tp. 2015.12147 
ficaciones se disponen de forma escalonada en terrazas, provoca que la atención se focalice en las viviendas. Frente a las grandes obras colectivas calcolíticas (sepulturas megalíticas, grandes fosos o complejas estructuras murarías), el énfasis en la nueva narrativa paisajística argárica se sitúa ahora en los poblados, en la imagen de fragmentación en múltiples unidades que ofrecería la visión de diferentes viviendas sobre una superficie de forma cónica.

La casa argárica supone una auténtica revolución, no sólo por situarse en el centro de una nueva realidad paisajística, sino también por los profundos cambios que se produjeron en su forma, diseño y características constructivas. Efectivamente, frente al hábitat calcolítico de cabañas circulares, exentas y distribuidas de forma dispersa, ahora se generalizan las viviendas de planta rectangular, trapezoidal o absidal que se yuxtaponen unas a otras creando un denso caserío (Fig. 1). Los espacios abiertos y de uso colectivo entre cabañas o conjuntos de cabañas, característicos de los poblados calcolíticos, quedan reducidos a estrechas callejuelas que apenas si permiten la circulación interna. La nueva casa argárica se configura como un espacio cerrado y compartimentado mediante tabicaciones que crean un sentido de "privacidad" ausente en las construcciones circulares calcolíticas. Esta nueva concepción urbana enfatiza la fragmentación y el acceso restringido, eliminado el sentido de colectividad presente en los espacios abiertos y en la idea de circularidad.

Todos estos cambios apuntarían hacia una nueva realidad social donde la unidad doméstica se erigiría como el espacio social por antonomasia integrando no sólo a los vivos sino también a los muertos, o al menos a una parte de ellos (1). Sin duda, uno de los cambios más profundos que acontecieron en época argárica fue la inclusión de las sepulturas en el interior de los poblados, habitualmente bajo los pisos de las viviendas, y el abandono de las prácticas de inhumación colec-

(1) La cantidad de tumbas documentadas en los asentamientos mejor conocidos, con la excepción, quizás, de El Argar y sus aproximadamente 1000 enterramientos, sugiere razones de naturaleza cultural en la elección de los individuos que finalmente recibían sepultura. Los cálculos realizados apuntan a una tasa de enterramientos del 20\% de la población (Chapman 1991) o, para caso concretos como el asentamiento de Fuente Álamo, incluso inferior, no superando el $14 \%$ del potencial número de fallecimientos (Bartelheim 2012).

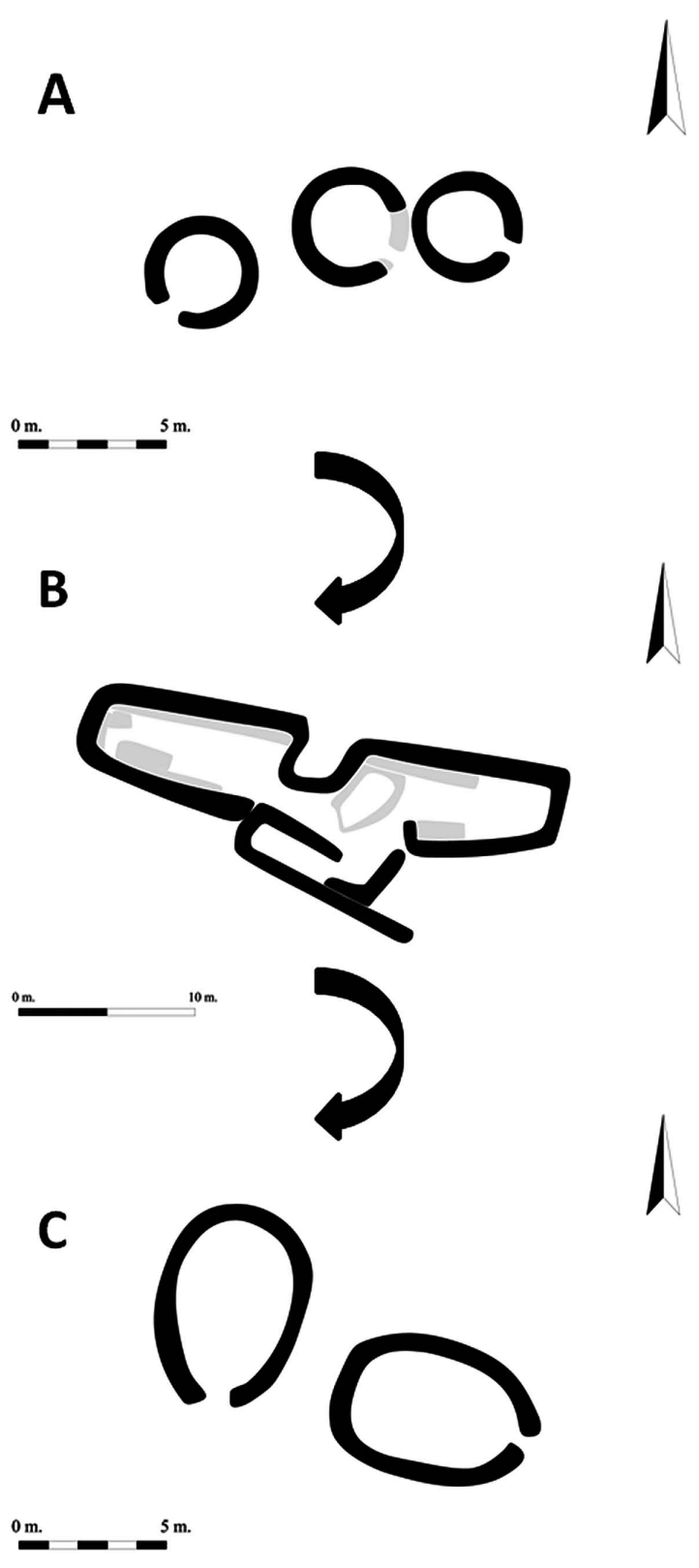

Fig. 1. Evolución de la arquitectura doméstica en las Edades del Cobre y Bronce del sureste peninsular: a. planimetría de varias cabañas calcolíticas del poblado de El Malagón (modificado a partir de Arribas et al. 1978); b. planimetría de una casa argárica de Peñalosa (modificado a partir de Contreras 2000); c. planimetría de dos cabañas del poblado del Bronce Final de la Serrecica (modificado a partir de Lomba 1998).

tiva por otras individuales. La integración de los enterramientos en el espacio doméstico reflejaría la nueva situación de fragmentación y división so- 
cial. Son ahora las relaciones familiares y genealógicas de los individuos que forman la casa las que quedarían representadas en las sepulturas. El abandono de prácticas rituales basadas en la desarticulación y agregación de huesos humanos y su sustitución por otras individuales y que mantienen los cuerpos articulados indicaría el desarrollo de rasgos de individualización en la identidad de las personas, que se irían haciendo visibles a costa de ocultar los vinculados con la identidad relacional o colectiva (Hernando 2002, 2012).

El proceso de fragmentación social e individualización estuvo igualmente acompañado de otro importante cambio consistente en la reorientación de las actividades en las que los excedentes son ahora invertidos. Este es el caso del proceso de intensificación de la producción metalúrgica
(Montero 1993, 1994). Los objetos metálicos se multiplicaron casi por cinco con respecto al periodo calcolítico destacando, muy especialmente, los adornos que supusieron más de la mitad de los objetos manufacturados y su creciente demanda estimuló significativas innovaciones, caso del desarrollo de la metalurgia de la plata (Bartelheim et al. 2012; Murillo-Barroso 2013) y de la introducción a partir del c. 1800 cal BC de las primeras aleaciones de cobre y estaño (Aranda et al. 2012; Murillo-Barroso et al. 2014).

El importante desarrollo de los adornos personales realizados en metal y su asociación a individuos concretos (Fig. 2) define a un grupo de hombres, mujeres y niños/as con una identidad relacional diferenciada del resto de la sociedad argárica que no tiene acceso a estos bienes de

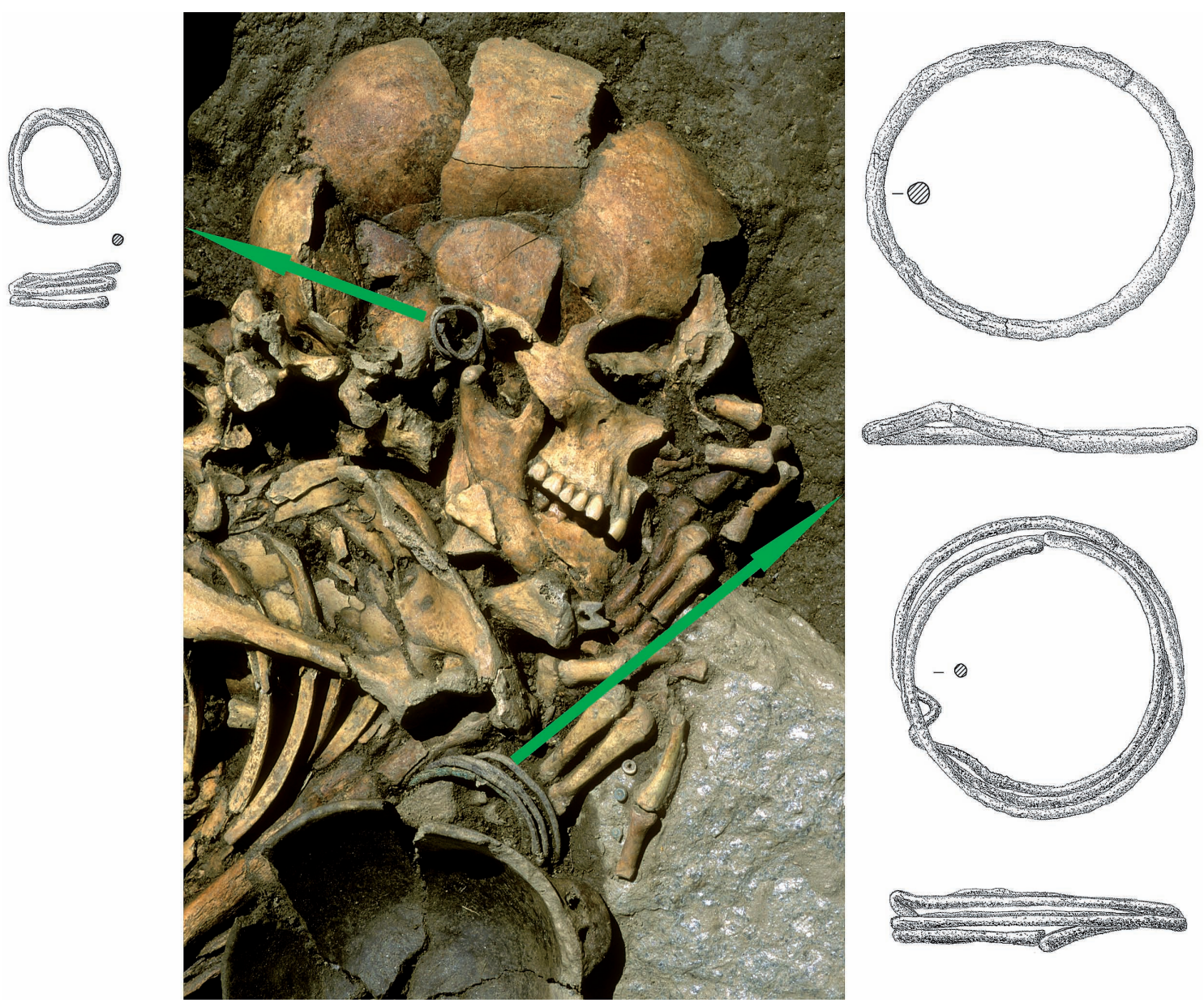

Fig. 2. Detalle del enterramiento masculino de la sepultura 21 del Cerro de la Encina con indicación de la localización de 2 pulseras asociadas al radio-cúbito derecho y de un pendiente al hueso temporal. 
consumo. Pero incluso dentro de este selecto grupo, que define a las denominadas élites argáricas, el proceso de individualización se manifiesta muy especialmente en las relaciones de género. Los hombres se asocian a espadas, alabardas y hachas y las mujeres a diademas y punzones, dos formas diferenciadas de expresión de la identidad. En el primer caso, son auténticos símbolos de ostentación al alcance sólo de reducido grupo de hombres. En el segundo, las diademas tendrían igualmente un sentido de exclusividad, dado el escaso número de ejemplares conocidos y su concentración geográfica. En cambio, los punzones cuantitativamente son abundantes y, además, aparecen asociados a mujeres de diversas categorías de edad y posición social. Este hecho enfatizaría la relevancia que mantendrían los mecanismos relacionales en la construcción de la identidad femenina, aparentemente menos individualizada que la masculina (Montón-Subías 2007, 2010; Sánchez-Romero 2008; Aranda et al. 2009).

Otro ámbito donde los excedentes subsistenciales son ahora invertidos consistiría en su consumo conspicuo en acontecimientos sociales de naturaleza competitiva como las prácticas de comensalidad asociadas al ritual funerario (Aranda y Esquivel 2007; Sánchez-Romero et al. 2007; Aranda 2008, 2010; Aranda y Montón-Subías 2011). Originalmente, este tipo de prácticas pudieron ser utilizadas por su capacidad de resistencia a la división social ya que se enfatizan valores colectivos como la hospitalidad o el compartir los bienes producidos, impidiendo de esta forma su acumulación. No obstante, las diferencias registradas en estas ceremonias dependiendo de la posición social del difunto o difunta (por ejemplo, el consumo de carne de bóvido se asocia exclusivamente a las élites sociales), nos situarían ante un tipo de ritual que trasciende el principio de reciprocidad para convertirse en un modo de representar y legitimar las asimetrías sociales. El excedente invertido en estos rituales se transformaría en bienes intangibles como el sentimiento de débito, miedo o inferioridad ante tal despliegue de riqueza, lo deseable de mantener relaciones de alianza con el organizador/es, la capacidad de atraer a aliados o de impresionar a los invitados. El consumo de bienes de alto valor social implicaría la inversión de capital económico en capital simbólico, lo que se traduce en la capacidad de influencia, reconocimiento del prestigio y del estatus (véase Dietler 2001; Hayden 2001, 2009). La fragmentación social argárica descansaría precisamente en la capacidad de determinadas familias e individuos de mantener e incrementar el capital simbólico.

En época argárica parece producirse, por tanto, una relajación del sistema de obligaciones y solidaridad que rige las estructuras de parentesco calcolíticas paralela a la importancia que adquiere la casa como unidad social básica. La tendencia a la fragmentación social y al creciente individualismo estaría directamente relacionada con la progresiva división de funciones, creciente especialización en actividades como la producción metalúrgica y en el consumo conspicuo de los excedentes en fiestas funerarias. Si valoramos el proceso de evolución social en su globalidad desde finales del IV milenio (c. 3200-1550 cal BC) parece evidente que el balance final indicaría un claro aumento en la complejidad. Si es así, y parece que existe un amplio acuerdo en la comunidad científica sobre este aspecto, deberíamos ser capaces de identificar y caracterizar las estrategias de resistencia que son inherentes a cualquier intento de explotación social y económica. A ello dedicaré el siguiente apartado.

\section{PRÁCTICAS DE RESISTENCIA DURANTE EL BRONCE ARGÁRICO}

El análisis de los fenómenos de resistencia apenas sí ha tenido cabida en los relatos sobre la complejidad social del sureste de la Península Ibérica. Las causas deben buscarse en la profunda influencia evolucionista en las narrativas sobre las sociedades pasadas, donde se han destacado todos aquellos elementos relacionados con el cambio, ya sea tecnológico, económico o social, marginando e invisibilizando los fenómenos de continuidad o resistencia cultural e ideológica, los denominados por James Scott (2003) como discursos ocultos. La sucesión ordenada de manifestaciones arqueológicas, periodos y culturas ha constituido el eje del discurso histórico de la Modernidad (Hernando 2002, 2012), al que no han escapado las sociedades analizadas en este trabajo.

No sorprenderá, por tanto, que las diferentes propuestas de explicación de los cambios que acontecieron en época argárica, ya sea desde posicionamientos difusionistas o autoctonistas, hayan

Trab. Prehist., 72, N. ${ }^{\circ}$ 1, enero-junio 2015, pp. 126-144, ISSN: 0082-5638

doi: $10.3989 /$ tp. 2015.12147 
compartido el énfasis en el análisis de las discontinuidades culturales, con el consiguiente olvido de aquellas dinámicas que pudiesen implicar la pervivencia de tradiciones anteriores. La transición respecto al periodo calcolítico se ha considerado como un proceso de sucesión ordenada -casi "natural" en ocasiones- entre grupos sociales culturalmente homogéneos. Es más, cualquier evidencia arqueológica que implicara cierta continuidad ha sido considerada como propia de comunidades marginales o "retardatarias", en proceso de desaparición o aculturación, que necesariamente terminarían ante el "empuje cultural", léase progreso cultural, de las sociedades argáricas, siguiendo, de esta forma, milimétricamente el discurso dominante de la Modernidad (Hernando 2012).

Recientemente, sin embargo, he cuestionado la sucesión ordenada y la pretendida unicidad cultural en la que se han basado la mayoría de los relatos sobre las sociedades argáricas, explorado la continuidad de formas culturales calcolíticas durante el II milenio cal BC (Aranda 2013, 2014; Aranda y Lozano 2014). Aunque se han comenzado a analizar tentativamente contextos domésticos de naturaleza hibrida donde se combinan elementos materiales característicos de tradiciones culturales diferenciadas (Aranda et al. 2015), han sido las prácticas de reutilización y permanencia en el uso de espacios funerarios característicos de época neolítica y calcolítica las que han ofrecido la información más cualificada para el estudio de estos fenómenos (Aranda 2013, 2014) (2).

Lejos de la consideración residual que habitualmente ha tenido el uso de estos espacios rituales en época argárica, el análisis de la documentación disponible muestra que al menos 63 contextos funerarios, entre sepulturas megalíticas y cuevas naturales y artificiales distribuidas por todo el sureste, fueron objeto de una intensa actividad ritual. Su distribución territorial afecta a las más importantes necrópolis megalíticas del sureste peninsular, a los principales conjuntos de cuevas artificiales conocidos, así como a un numeroso grupo de cuevas naturales que tienden a concentrarse en aquellas comarcas donde el fenómeno megalítico posee menor entidad

(2) Este tipo de fenómenos son igualmente habituales en otras comarcas y regiones de la Península Ibérica (Kalb 1994; Delibes 2004; García Sanjuán 2005, 2011; Mataloto 2007; Aranda et al. 2013) y de Europa (Holtorf 1997, 1998; Bradley 2002).
(Fig. 3). Este es el caso de determinados territorios murcianos, jienenses o granadinos, en donde parece documentarse una cierta separación espacial entre contenedores funerarios megalíticos y en cueva. Desafortunadamente, la investigación sobre este tipo de espacios rituales cuenta con algunas deficiencias relevantes. Al poco interés que su indagación ha suscitado en las últimas décadas se une el expolio al que recurrentemente se han visto sometidos, la antigüedad de la mayoría de sus excavaciones y la no publicación o publicación parcial de las más recientes. Todo ello redunda en que la calidad de la información actualmente disponible para su estudio no sea la deseable.

La materialidad que identifica a las prácticas de reutilización ha consistido en la documentación de ajuares funerarios de tipología argárica cuyas características formales y tecnológicas son indistinguibles de los que aparecen en las sepulturas del interior de los poblados. Se trata fundamentalmente de recipientes cerámicos, entre los que destacan formas clásicas como las copas, y objetos metálicos como los puñales de remaches, punzones, brazaletes, cuentas, anillos y pendientes (Fig. 4). Sorprende la intensidad y persistencia con la que algunas de estas sepulturas fueron reutilizas. Este es el caso de diferentes tumbas megalíticas de necrópolis granadinas como Los Eriales, Las Peñuelas (Leisner y Leisner 1943) o El Pantano de los Bermejales (Arribas y Ferrer 1997) donde los ajuares de tipología argárica se cuentan por decenas.

Estos ajuares acompañan a inhumaciones que fueron depositadas en el interior de cuevas o sepulturas megalíticas. Donde ha sido posible documentar prácticas de reutilización con metodología arqueológica es habitual la presencia de importantes secuencias de enterramientos cuyos restos antropológicos aparecen en diferente grado de articulación. No obstante, también se han registrado algunos casos singulares. Por ejemplo, en la sepultura 5 de la necrópolis megalítica de El Barranquete (Nijar, Almería) (Almagro Gorbea 1973), se documentaron dos enterramientos individuales en fosa situados en su túmulo y no en la cámara funeraria como es habitual. Igualmente excepcionales son varias sepulturas megalíticas de Las Peñas de los Gitanos (Montefrío, Granada), donde no sólo se reutilizaron las cámaras sepulcrales sino que se modificaron sus dimensiones

Trab. Prehist., 72, N. ${ }^{\circ}$ 1, enero-junio 2015, pp. 126-144, ISSN: 0082-5638 doi: $10.3989 /$ tp.2015.12147 


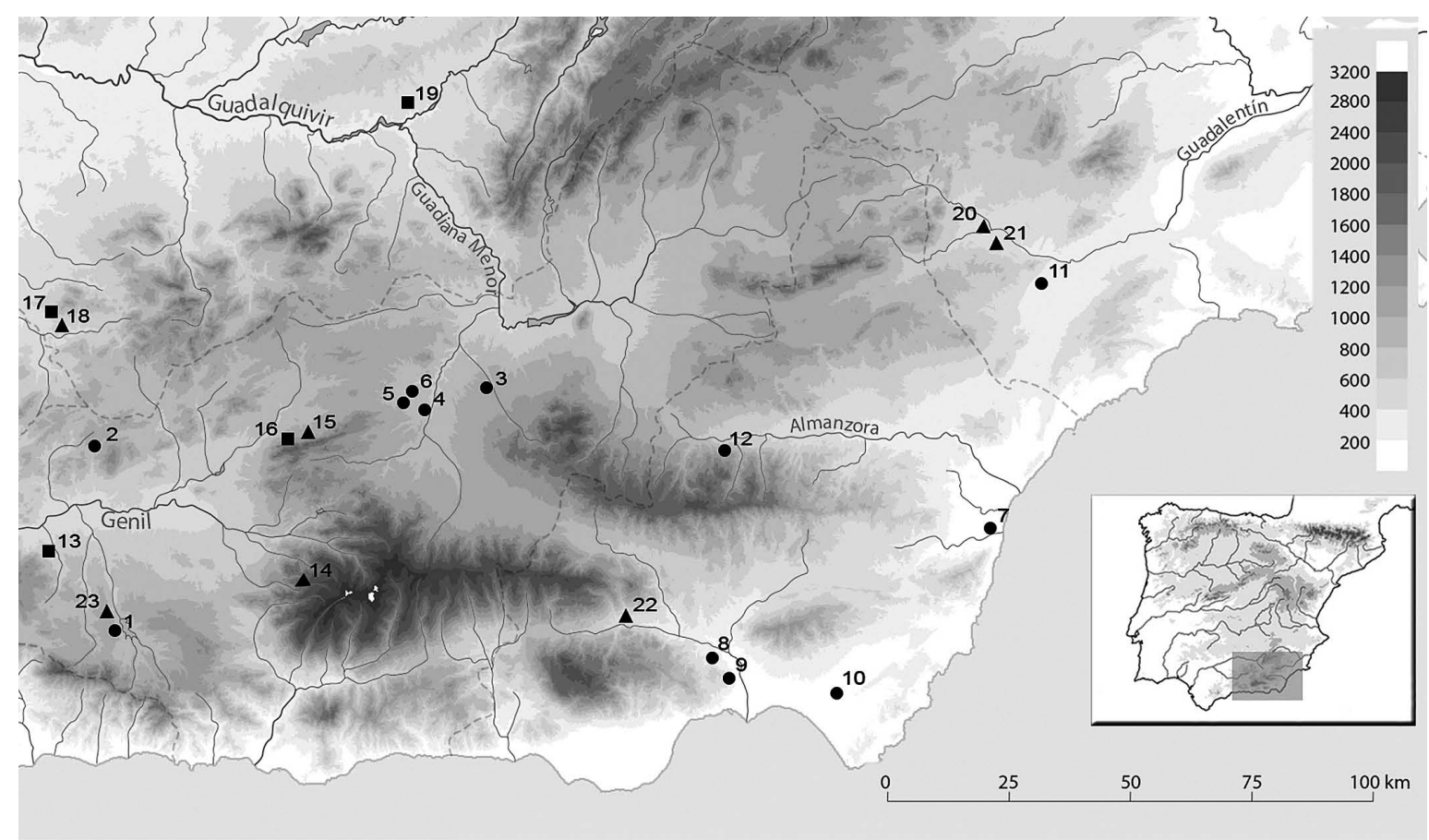

Fig. 3. Sitios con prácticas rituales y funerarias de reutilización durante la Edad del Bronce argárica: Megalitos; A Cuevas naturales; Cuevas artificiales. Granada: 1 Pantano de los Bermejales; 2 Peñas de los Gitanos; 3 Gor; 4 Fonelas; 5 Huélago; 6 Laborcillas; 13 Covacha de la Presa; 14 Cuevas de Los Tejones, La Vieja, El Moro y La Paloma; 15 Cuevas de la Carigüela, La Pintá y Las Ventanas; 16 Cerro del Greal; 23 Tajos del Río Cacín. Almería: 7 Mojácar; 8 Los Millares; 9 El Chuche; 10 El Barranquete; 12 Purchena; 22 Cueva Bajica. Murcia: 11 Murviedro; 20 Cueva de los Alcores; 21 Cuevas del Calor y del Barranco del Saltador. Jaén: 17 Marroquies Altos; 18 Cueva de Caño Quebrado; 19 La Sima. Base cartográfica: Modelo Digital del Terreno de Andalucía (vuelo fotogramétrico a 1:20.000 de 2001-2002).

para adaptarlas a las proporciones de una cista (Mergelina 1941-42).

Para entender mejor la dimensión temporal y la intensidad en la reutilización de estos espacios funerarios el análisis tipológico presenta algunas limitaciones importantes. La indefinición cronológica y cultural de determinados elementos materiales que poseen una larga perduración sin modificar sus características formales o tecnológicas es una de ellas. Además, desde el análisis tipológico, no es posible considerar todas aquellas prácticas sociales que hayan podido suponer enterramientos sin ajuares o que, resultado del expolio continuado de estos espacios, no se hayan conservado. De esta forma, un conjunto potencialmente importante de rituales realizados en momentos culturales posteriores a los fijados por la investigación tradicional para este tipo de sepulcros han podido quedar completamente ocultos tras nuestras limitaciones analíticas.
Las dataciones radiocarbónicas sobre restos antropológicos emergen como una posible alternativa para intentar solventar algunas de estas limitaciones. Con este objetivo en mente hemos recientemente desarrollado un programa de dataciones en dos fases. En una primera fase el propósito principal consistió en contrastar la tradicional asunción que limitaba la reutilización de estos espacios funerarios a los momentos más antiguos de la Edad del Bronce. Para ello se realizaron 7 nuevas dataciones: tres correspondientes a la sepultura 11 de la necrópolis megalítica de El Barranquete (Níjar, Almería), tres a la sepultura 8 del Pantano de los Bermejales (Arenas del Rey, Granada) y una procedente de las excavaciones realizadas en la cueva de Las Ventanas (Piñar, Granada). Todas ellas fechaban prácticas de inhumación realizadas durante la Edad del Bronce. La suma de estas nuevas dataciones con las ya conocidas (Fig. 5) mostraba un uso funerario 


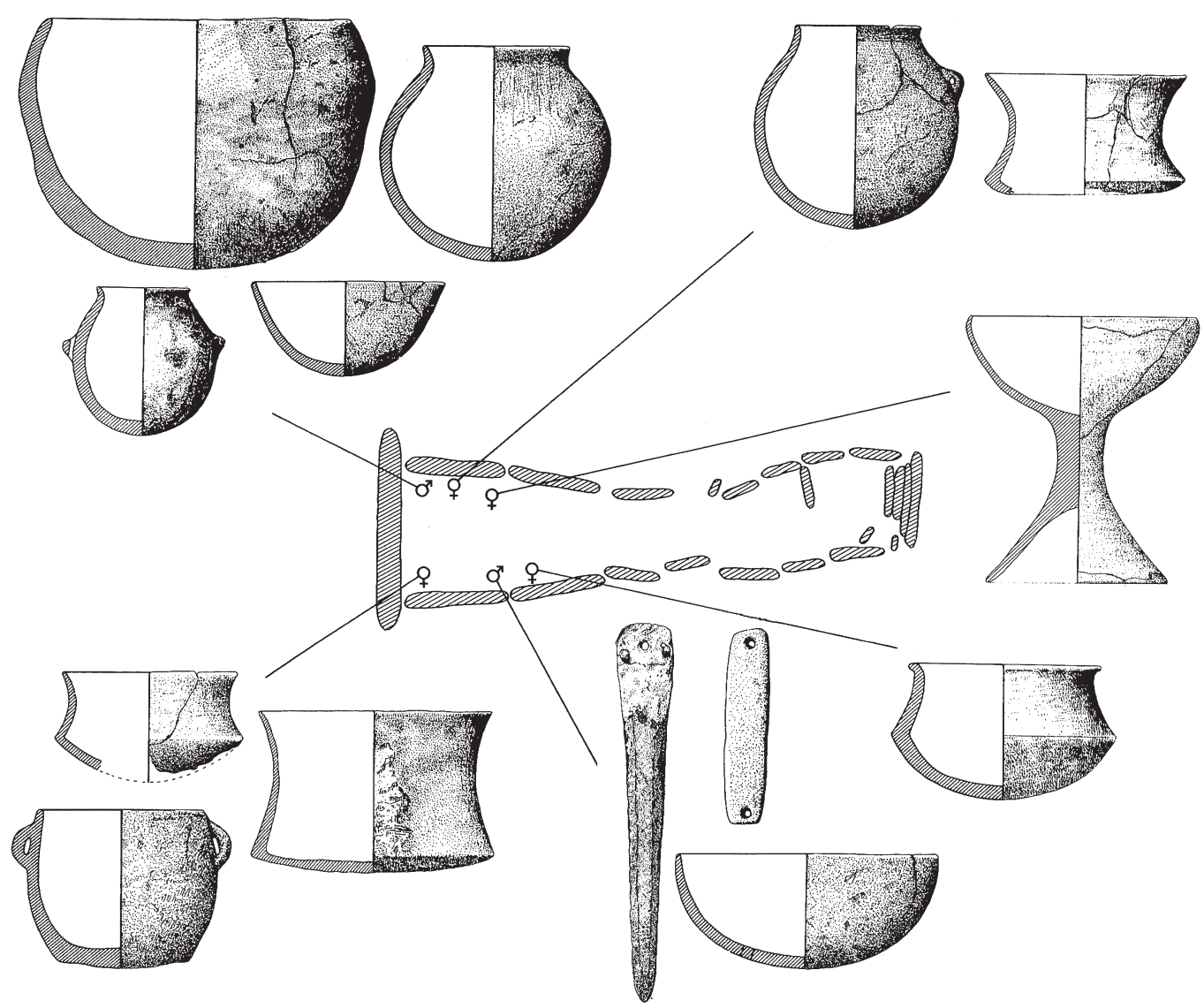

Fig. 4. Sepultura 8 de la necrópolis del Pantano de los Bermejales con representación de parte de sus ajuares funerarios (a partir de Arribas y Ferrer 1997).

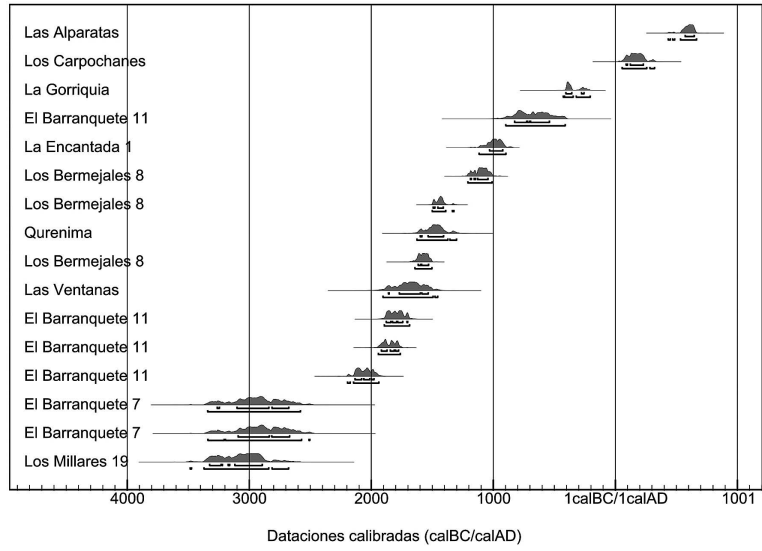

Fig. 5. Distribución combinada de las dataciones de sepulturas colectivas de la Prehistoria Reciente del sureste peninsular. Programa de calibración OxCal v. 4.2.4 (Bronk Ramsey 2009), curva de calibración (IntCal13) (Reimer et al. 2013; Aranda 2013). continuado desde finales del IV milenio hasta los últimos siglos del I milenio cal BC, manteniéndose incluso en época histórica. En lo referente al tiempo argárico, la continuidad y frecuentación de estos espacios funerarios quedada fuera de toda duda (Aranda 2013, 2014).

A partir de estas conclusiones hemos realizado una segunda fase de dataciones con el objetivo de poder medir la importancia de estas prácticas en la globalidad de los rituales realizados en una sepultura y contar con una serie radiométrica estadísticamente significativa con la que poder generar modelos cronológicos (Aranda y Lozano 2014). Para ello hemos datado el número mínimo de individuos de la sepultura 11 de la necrópolis de El Barranquete; en total 12 individuos que se distribuyen a lo largo de los diferentes niveles de excavación identificados por sus excavadores. Los resultados muestran un uso continuado de 
la sepultura desde mediados de III milenio hasta al menos finales del II milenio cal BC (Fig. 6). De las 12 dataciones cinco, algo más del $40 \%$, fechan prácticas rituales pertenecientes a la Edad del Bronce, muy especialmente al Bronce argárico. La escala e intensidad en la reutilización de esta sepultura es ciertamente notable y aunque estos datos no sean extrapolables a otras tumbas o necrópolis sí que evidencian una realidad hasta hace poco tiempo difícilmente imaginable.

La reutilización de espacios funerarios característicos de época calcolítica debe considerarse, por tanto, una fenómeno habitual en época argárica. Superada la consideración marginal de estas prácticas rituales, la recuperación de la agencia de estos grupos sociales permite avanzar en nuevas formulaciones sobre la complejidad social. En este sentido, he planteado recientemente que la reutilización de espacios megalíticos y cuevas naturales $\mathrm{y}$ artificiales podría formar parte de estrategias de resistencia ante el proceso de diferenciación social que caracterizó a las comunidades argáricas (Aranda 2013, 2014). La respuesta a los intentos de explotación social y económica consistiría en el mantenimiento y reivindicación de la tradición $\mathrm{y}$ de formas culturales ancestrales, mediante las que se ensalzaría a la comunidad y reclamaría el principio de indivisión social frente al proceso de individualización argárico. Los espacios rituales colectivos se convertirían, de esta forma, en el

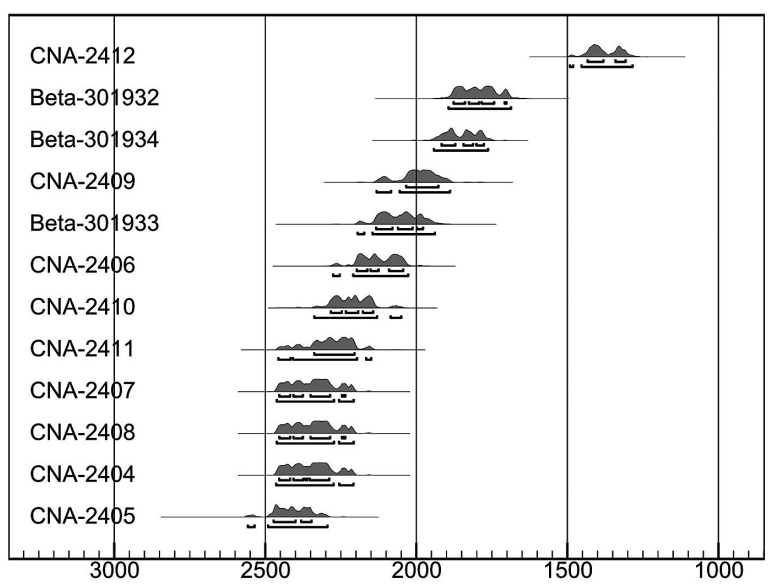

Fig. 6. Distribución combinada de las dataciones de sepultura 11 de la necrópolis de El Barranquete (Nijar, Almería). Programa de calibración OxCal v. 4.2.4 (Bronk Ramsey 2009), curva de calibración (IntCal13) (Reimer et al. 2013; Aranda y Lozano 2014). escenario perfecto para manifestar la oposición al principio de "trabajar para otros" que hábilmente intentaban consolidar las élites argáricas, reorientando la inversión del excedente hacia su consumo conspicuo en prácticas comensales o al desarrollo de una metalurgia dirigida a la creación de toda una simbología de la individualidad.

En el intento de acentuar el sentido de colectividad presente en las prácticas de reutilización, resulta ciertamente significativa la ausencia de aquellos ajuares que denotarían un mayor grado de exclusividad e individualización. Nos referimos a elementos como las alabardas o diademas, completamente desconocidos en estos contextos, o a espadas y hachas cuya presencia en sepulturas megalíticas y cuevas es completamente testimonial (3). La incorporación de ajuares argáricos a sepulturas colectivas parece seguir estrategias que suponen la exclusión de los símbolos más genuinamente asociados al poder, aquellos que identificaban a hombres y mujeres como los miembros más destacados entre las élites sociales argáricas. No parece casual que de la variedad de ajuares funerarios los únicos ausentes en las prácticas de reutilización sean justo los que se relacionan con la construcción de aquellas identidades más individualizadas que ocuparían la cúspide de la pirámide social.

Las prácticas de reutilización enfatizarían un tipo de conmemoración basado en los ancestros donde el enterramiento formaría parte del propio ritual, de forma sustancial si se quiere, pero no sería el elemento central que las define (Barrett 1988). La invocación al pasado, a la memoria colectiva ocuparía, sin embargo, un lugar preeminente que conecta con formas comunitarias de comprensión de la realidad y de legitimidad social. Frente a esta situación, los rituales funerarios específicamente argáricos estarían especialmente centrados en el enterramiento. El ritual gira ahora en torno a la inhumación donde el individuo pasa a ser el protagonista. Obviamente, no significa que en estas prácticas no se realicen invocaciones a un pasado y a unas genealogías específicas, simplemente el acento se ha trasladado a otros

(3) Sólo se conoce un hacha de tipología argárica documentada en la sepultura megalítica de Los Eriales 10 (Laborcillas, Granada) (Leisner y Leisner 1943). El único ejemplar de espada contextualizado procede de la cueva de Las Ventanas (Riquelme et al. 2001; Riquelme 2002).

Trab. Prehist., 72, N. ${ }^{\circ}$ 1, enero-junio 2015, pp. 126-144, ISSN: 0082-5638

doi: $10.3989 /$ tp.2015.12147 
aspectos de la realidad social que interesa exhibir y naturalizar. Se produce, de esta forma, una contradicción entre las formas culturales argáricas basadas en la individualidad y aquellas otras que defienden un identidad relacional; contradicción porque las primeras tratan de superar a las segundas creando nuevas estructuras sociales basadas en la emergencia de un grupo social separado del cuerpo social y las segundas ofrecen una pertinaz resistencia a este proceso.

En época argárica se produciría, por tanto, una importante tensión social, resultado de la convivencia de sectores sociales caracterizados por formas sociales cada vez más asimétricas y aquellos otros que contraponen el uso de espacios rituales colectivos y su conexión con los ancestros como mecanismo de resistencia frente a los intentos de establecer un nuevo orden social. Pero, ¿cómo se resolvió esta tensión?, ¿el proceso de individualización supuso la ruptura definitiva de las relaciones parentales?, ¿se mantuvieron en el tiempo las prácticas de reutilización o desaparecieron de forma drástica como sucedió con las formas culturales argáricas? Para intentar dar respuesta a estos interrogantes, en el siguiente apartado, trataré de analizar cuáles son las principales características de las comunidades posteriores, agrupadas tradicionalmente en el denominado Bronce Tardío y Final del sureste.

\section{LAS SOCIEDADES DEL BRONCE TARDÍO Y FINAL DEL SURESTE}

Aproximarnos al estudio de las sociedades posteriores al Bronce argárico supone enfrentarnos a la que podríamos denominar como "la hermana pobre" de la Prehistoria Reciente del sureste. Frente al considerable volumen de investigación desarrollado, especialmente en los últimos 40 años, en torno a las sociedades de las Edades del Cobre y Bronce argárico, el conocimiento sobre las comunidades de Bronce Tardío y Final (c. 1550-900 cal BC) apenas si ha conseguido incorporar nueva información. Esta falta de interés y consiguiente vacío de investigación no nos sorprende ni pensamos sea inocente, especialmente si consideramos la perspectiva evolucionista que ha inspirado el discurso histórico de la Modernidad. El foco de atención ha quedado, de esta forma, centrado en los grupos sociales que protagonizaron el proceso histórico que conducía hacia formas sociales y económicas cada vez más complejas, quedando fuera de la agenda de investigación aquellas otras comunidades que no encajaban en este discurso. Este sería el caso, por ejemplo, del Bronce Final, considerado como con un periodo de transición o formativo de las posteriores sociedades de la Edad del Hierro, una especie de paréntesis histórico entre las elaboradas formas de asimetría social argárica y las aristocracias ibéricas.

Efectivamente, el colapso de las sociedades argáricas supuso el final de sus características prácticas sociales y económicas. Aunque posiblemente no todos los cambios se produjeron de manera simultánea en el extenso territorio argárico, sí es cierto que en torno al c. $1550-1500$ cal BC se habría prácticamente abandonado el elemento cultural más definitorio de estas comunidades, su ritual de enterramiento en el interior de los poblados. Otras relevantes transformaciones supusieron el abandono o reestructuración de los poblados de acuerdo con nuevos principios arquitectónicos y la desaparición de algunos de los materiales cerámicos y metálicos más característicos de época argárica. Todos estos cambios condujeron a un proceso de fragmentación social y económica del sureste que en torno al c. $1300 \mathrm{cal} \mathrm{BC}$ dio paso a las comunidades del Bronce Final.

A pesar de la anteriormente mencionada exigua investigación desarrollada para este periodo, sus principales aspectos culturales apuntan hacia formas sociales y económicas de menor complejidad donde la colectividad y las identidades relacionales parecen imponerse. Este sería el caso de las nuevas formas arquitectónicas y urbanísticas. Especialmente durante el Bronce Final, se generaliza un tipo de vivienda de planta circular u ovalada con alzados de tapial o adobe, habitualmente sobre zócalos de piedra, y sin ningún tipo de compartimentación interna (Fig. 1). Estas cabañas aparecen exentas y se distribuyen de forma dispersa con amplios espacios abiertos entre ellas. El abandono del urbanismo compacto, basado en construcciones rectangulares y compartimentadas, y la generalización de la arquitectura circular y exenta evidenciarían el importante cambio experimentado en las formas de representación de la realidad y en la instauración de un nuevo orden social y económico. La fragmentación y división social argárica y su materialización arquitectónica

Trab. Prehist., 72, N. ${ }^{\circ}$ 1, enero-junio 2015, pp. 126-144, ISSN: 0082-5638 doi: $10.3989 /$ tp. 2015.12147 
fue sustituida por formas urbanísticas que dificultan la compartimentación y favorecen la integración e inclusión social.

Junto a los cambios urbanísticos, la enorme relevancia que adquirió la metalurgia argárica en el desarrollo de las asimetrías sociales queda ahora reducida a una actividad de menor envergadura. Durante el Bronce Tardío o Postargar la interrupción de las prácticas funerarias al interior de los poblados supuso igualmente una importante reducción en la producción de los objetos metálicos, especialmente de aquellos relacionados con las nuevas formas de identidad argáricas. Durante este periodo, se registran fundamentalmente herramientas como punzones, cinceles o puntas de flecha. También son habituales las evidencias relacionadas con el proceso de manufactura. Este sería el caso de crisoles, moldes y escorias hallados en poblados como Fuente Álamo, Gatas o Murviedro (Castro et al. 1999; Risch 2002; Pujante Martínez et al. 2003). Todo ello apuntaría hacia una metalurgia de tipo doméstico orientada a la producción fundamentalmente de útiles y herramientas destinadas a un consumo local (4).

Por su parte, la metalurgia del Bronce Final supuso la introducción de nuevos objetos con características formales y tecnológicas diferentes. En estos momentos se produjeron mayoritariamente objetos de adorno como brazaletes, torques, anillos, pendientes, cuentas de collar, fíbulas, botones, eslabones etc. en algunas ocasiones, especialmente en los brazaletes, decorados con motivos geométricos (Lorrio 2008, 2011). La presencia de otros metales como las puntas de flecha, punzones, agujas, espadas o hachas en sus diferentes variantes tipológicas fue mucho más testimonial (Molina 1978). El bronce es el metal usado habitualmente, aunque también se han registrado cobres, cobres arsenicados y aleaciones ternarias. Sin embargo, el empleo del oro y la plata fue completamente excepcional (Montero 2008). Las evidencias relacionadas con el proceso de producción son muy fragmentarias, destacando la documentación de algunos moldes de fundición

(4) El poblado de Cabezo Redondo y la orfebrería tipo Villena (tesoros de Cabezo Redondo y Rambla de Panadero) (Soler 1965, 1987; Hernández Pérez 2012) representan un fenómeno excepcional a esta situación que, en cualquier caso, quedaría fuera del territorio argárico clásico (Jover Maestre y López Padilla 1995, 1999).
(Molina 1978) y el reciente hallazgo de un taller metalúrgico en Guadix, aunque de cronología muy tardía (Carrasco et al. 2002). Los espacios funerarios se convirtieron de nuevo en el contexto principal donde se depositaron los objetos metálicos, muy especialmente los adornos.

Frente al proceso de intensificación de la producción metalurgia argárica, durante el periodo tratado en este apartado (c. 1550-900 cal BC) se produjeron relevantes cambios que apuntan hacia una menor división de funciones y especialización artesanal. El exiguo volumen de objetos producidos (5) y la escasez de evidencias relacionadas con el proceso de manufactura nos sitúan ante un tipo de metalurgia con una baja escala de producción, integrada, en cualquier caso, dentro de amplias redes de intercambio. A diferencia de época argárica, el sureste pasó a formar parte de circuitos mediterráneos, atlánticos y peninsulares de distribución de objetos metálicos y probablemente materias primas. Otro importante cambio consistió en la práctica desaparición de la orfebrería, especialmente de la plata que había alcanzado un muy relevante grado de desarrollo en época argárica. Sorprende, igualmente, la escasez tanto de armas especializadas (6) como de herramientas, algunas de ella tan características como los cuchillos/puñales argáricos que durante el Bronce Final no son sustituidos por ningún otro objeto metálico. La metalurgia, especialmente de la etapa final, estuvo orientada hacia la producción de objetos de adorno que debieron formar parte de nuevas formas de identidad, muy posiblemente de tipo relacional o colectivo si tenemos en cuenta el tipo de práctica ritual del que formaron parte, tal y como a continuación se valorará.

Las prácticas funerarias de este periodo ( $c$. 1550-900 cal BC) se caracterizan por una cierta heterogeneidad ritual. Algunas sepulturas de carácter colectivo combinaron prácticas de incineración e inhumación caso por ejemplo de Qurénima, Barranco Hondo, Cabezo Colorado y Caldero de Mojácar o únicamente de inhumación como en Campos o Loma de la Gorriquía, todos ellas en

(5) El peso total de los objetos metálicos documentados en las sepulturas del Bronce Final apenas supera los $2 \mathrm{~kg}$ (Lorrio 2008), lo que contrasta con los $2,7 \mathrm{~kg}$ sólo de los adornos argáricos realizados en plata (Murillo Barroso 2013) y los aproximadamente $96 \mathrm{~kg}$ de metal argárico (Montero 1992).

(6) Sólo se conocen 5 ejemplares de espadas (Lorrrio 2008).

Trab. Prehist., 72, N. ${ }^{\circ} 1$, enero-junio 2015, pp. 126-144, ISSN: 0082-5638

doi: $10.3989 /$ tp.2015.12147 
la cuenca de Vera. De forma más excepcional, también se han documentado sepulturas exclusivamente de incineración aisladas o formando pequeñas necrópolis, caso de Parazuelos (Mazarrón, Murcia), Ballabona (Cuevas del Almanzora, Almería) (Siret y Siret 1890; Siret 2001; Lorrio 2008, 2011) o el hallazgo más reciente de Llano de los Ceperos (Lorca, Murcia) (Ros Sala 1985). No parece que las nuevas sepulturas o necrópolis típicas de estos momentos fueran una práctica muy extendida y, en cualquier caso, se trata de enterramientos territorialmente concentrados en las comarcas litorales de Almería y Murcia.

Sin embargo, el tipo de ritual más recurrente y extendido geográficamente a las diferentes comarcas que configuran el sureste consistió en la reutilización de sepulturas megalíticas y en menor medida de cuevas naturales y artificiales. La inhumación y, de forma más excepcional, la cremación en el interior de estos espacios de enterramiento colectivo se convirtió en la práctica funeraria más habitual de este periodo (7). Así lo confirmarían las evidencias de ajuares funerarios, tipológica y tecnológicamente adscribidles a este periodo, los restos antropológicos asociados (Lorrio 2008, 2011), y las recientes dataciones radiocarbónicas (Lorrio y Montero 2004, 2008; Aranda 2013, 2014; Aranda y Lozano 2014). Al margen de la variabilidad en las prácticas funerarias de este periodo, existen varios elementos comunes a todas ellas: el carácter fundamentalmente colectivo de los enterramientos, su localización al exterior de los poblados y el tipo de ajuar, compuesto de forma prácticamente invariable por objetos de adorno realizados en metal aunque también en otras materias primas como el hueso, la pasta vítrea, el ámbar y la piedra (8).

\section{CONCLUSIONES}

Si valoramos diacrónicamente los cambios y continuidades que se produjeron a lo largo de la

(7) Según Alberto Lorrio $(2008,2011)$ de los 58 conjuntos funerarios adscritos al Bronce Final 40, el 69\%, pertenecen a reutilizaciones de sepulturas megalíticas.

(8) Aunque en algún caso las vasijas cerámicas pudieron haber formado parte de los ajuares, la mayoría de ellas deben considerarse como recipientes funerarios (urnas y tapaderas) (Lorrio 2008).
Edad del Bronce podríamos concluir que el fenómeno de resistencia al proceso de individualización social argárico fue exitoso. Así, las tensiones sociales que se producirían en época argárica entre las formas de identidad social individualizada y aquellas otras más colectivas y relacionales se resolverían a favor de estas últimas. Si atendemos a las características culturales de las comunidades del Bronce Tardío y Final, las relaciones de parentesco y los principios de solidaridad y reciprocidad parece que de nuevo se convirtieron en dominantes (9). Varios argumentos apoyan esta valoración.

a) La drástica desaparición de los enterramientos individuales en el interior de los poblados y de los símbolos característicos de las élites argáricas (p.e. la orfebrería de la plata), lo que se contrapone con la continuidad e intensidad en la reutilización de sepulturas megalíticas y, en menor medida, de cuevas naturales y artificiales. Además, el uso de estos espacios rituales es la única práctica funeraria identificada en amplios territorios del sureste.

b) El enterramiento colectivo se impone como práctica generalizable a todo el sureste, no sólo gracias a la reutilización de sepulturas megalíticas o cuevas sino también en aquellos otros enterramientos que fueron construidos en estos momentos. Este es el caso, muy especialmente, de las sepulturas que combinan en el mismo espacio inhumaciones e incineraciones y que son características sobre todo de la cuenca de Vera. La vinculación con el pasado, la memoria y los ancestros situaría de nuevo a la comunidad y a las identidades relacionales en el centro de las formas de compresión de la realidad. Lo individual quedaría de esta forma diluido en lo colectivo.

c) La acumulación de excedentes subsistenciales y su inversión en otras actividades o bienes de consumo parece sufrir un importante retroceso en estos momentos. Durante el Bronce Tardío y Final no hay nada parecido a las construcciones monumentales calcolíticas (complejos sistemas

(9) No debe confundirse la resistencia y la reivindicación de lo colectivo con la inexistencia de formas diferenciadas de acceso a los bienes producidos sino simplemente una sociedad ordenada por el parentesco y, por tanto, condicionada por unas relaciones de reciprocidad que limitan y restringen las posibles desigualdades sociales (Vicent 1988). 
de fosos, estructuras murarías, sepulturas megalíticas etc.), al desarrollo de artesanías especializadas como la precedente metalurgia argárica, $\mathrm{o}$ al consumo conspicuo de excedentes en fiestas de comensalidad. Sólo algunas evidencias, caso de determinadas cerámicas, objetos metálicos o elementos de adorno realizados en ámbar o pasta vítrea, reflejarían la inversión de excedentes en la adquisición de bienes procedentes de otros ámbitos culturales. En cualquier caso, el volumen de objetos con estas características indicaría una escasa participación de las comunidades del sureste en las redes de intercambio. La estructura socioeconómica de este periodo (c. 1550-900 cal $\mathrm{BC}$ ) se caracterizaría por una escasa división de funciones y especialización en el trabajo.

d) El éxito de las nuevas identidades colectivas y relacionales tendría una de sus manifestaciones más significativas en la vuelta a la idea de circularidad. En la organización del espacio terminó imponiéndose una arquitectura dominada por formas circulares y ovaladas tanto en las casas como en las sepulturas que se reutilizan o construyen en estos momentos. El sentido de compartimentación y privacidad de los momentos culturales previos dio paso una nueva percepción del orden social y económico donde la circularidad puede ser considerada como metáfora de una realidad donde las partes sólo son comprensibles desde el todo, de una realidad indivisa y cíclica.

El proceso de recuperación de formas mucho más colectivas de organización social, basadas en estructuras socioeconómicas con escasa división de funciones, y el énfasis en nuevas identidades de tipo relacional parecen imponerse a lo largo de la segunda mitad del II milenio. Así, el proceso de jerarquización social argárico y su correlato político, estatal o no, supuso una particular trayectoria histórica que terminó con su disolución ante formas sociales más igualitarias y menos jerarquizadas. No va a ser hasta la Edad del Hierro cuando el desarrollo de las aristocracias ibéricas permita plantear para el sureste peninsular un nuevo orden social y económico.

Tal y como planteábamos al comienzo del presente trabajo los discursos sobre el pasado no son inocentes y, por supuesto, no lo es el que acabamos de realizar. El análisis de las sociedades de la Prehistoria Reciente del sureste peninsular, un caso de estudio paradigmático sobre el origen y desarrollo de la complejidad social, muestra cómo los procesos resistencia ante los intentos de opresión y coerción socioeconómica pueden ser exitosos. La vuelta a formas de organización mucho más igualitarias y de menor complejidad se presenta como un camino no sólo deseable sino posible. Las sociedades de la Edad del Bronce son un buen ejemplo de cómo valores como la individualidad o desigualdad fueron sustituidos por otros como la solidaridad y la reciprocidad.

\section{AGRADECIMIENTOS}

Mi más sincero agradecimiento a los comentarios y sugerencias de la primera versión de este trabajo realizados por Almudena Hernando Gonzalo, Paloma González Marcén, Leonardo García Sanjuán, Antonio Blanco González y Margarita Sánchez-Romero. El presente artículo ha sido realizado en el marco del Proyecto de Investigación "Innovación, continuidad e hibridación. Las sociedades de las edades del cobre y bronce en el sur de la península ibérica" (HAR2013-42865-P) y del Grupo de Investigación "GEA Cultura material e identidad social en la Prehistoria Reciente en el sur de la Península Ibérica" (HUM-065).

\section{BIBLIOGRAFÍA}

Almagro Gorbea, M. J. 1973. El poblado y la necrópolis de El Barranquete (Almería). Acta Arqueológica Hispánica VI, Ministerio de Educación y Ciencia. Madrid.

Aranda Jiménez, G. 2008: “Cohesión y distancia social. El consumo comensal de bóvidos en el ritual funerario de las sociedades argáricas". Cuadernos de Prehistoria y Arqueología de la Universidad de Granada 18: 107-23.

Aranda Jiménez, G. 2010: “Entre la tradición y la innovación: el proceso de especialización en la producción cerámcia argárica". Menga. Revista de Prehistoria de Andalucía 1: 77-95.

Aranda Jiménez, G. 2013: "Against Uniformity Cultural Diversity: The "Others" in Argaric Societies". En M. Cruz Berrocal, L. García Sanjuán y A. Gilman (eds.): The Prehistory of Iberia. Debating Early Social Stratification and the State. Routledge. New York: 99-118.

Aranda Jiménez, G. 2014: "La memoria como forma de resistencia cultural. Continuidad y reutilización de espacios funerarios colectivos en época argárica". 
En E. García Alfonso (ed.): Movilidad, contacto y cambio. II Congreso de Prehistoria de Andalucía (Antequera 2012). 255-77. Sevilla.

Aranda Jiménez, G.; Alarcón, E.; Murillo Barroso, M.; Montero, I.; Jiménez-Brobeil, S.; Sánchez-Romero, M. y Rodríguez-Ariza, M. O. 2012: "El yacimiento argárico del cerro de San Cristóbal (Ogíjares, Granada)". Menga. Revista de Prehistoria de Andalucía 3: 141-65.

Aranda Jiménez, G. y Esquivel, J. A. 2007: “Poder y prestigio en las sociedades de la cultura de El Argar. El consumo comunal de bóvidos y ovicápridos en los rituales de enterramiento". Trabajos de Prehistoria 64 (2): 95-118.

Aranda Jiménez, G.; García Sanjuán, L; Lozano Medina, A. y Costa Caramé, M. E. 2013: "Nuevas dataciones radiométricas del dolmen de Viera (Antequera, Málaga). La Colección Gómez-Moreno". Menga. Revista de Prehistoria de Andalucía 4: 243-58.

Aranda Jiménez, G. y Lozano Medina, A. 2014: “The chronology of megalithic funerary practices: a Bayesian approach to Grave 11 at El Barranquete necropolis (Almería, Spain)". Journal of Archaeological Science 50: 369-382.

Aranda Jiménez, G. y Montón-Subías, S. 2011: “Feasting Death: Funerary Rituals in the Bronze Age Societies of South-eastern Iberia". En G. Aranda Jiménez, S. Montón-Subias y M. Sánchez-Romero (eds.): Guess Who's Coming to Dinner. Feasting Rituals in the Prehistoric Societies of Europe and Near East. Oxbow Book. Oxford: 130-157.

Aranda Jiménez, G.; Montón Subías, S. y SánchezRomero, M. 2015: The Archaeology of Bronze Age Iberia: Argaric Societies. Routledge. New York.

Aranda Jiménez, G.; Montón Subías, S.; Sánchez-Romero, M. y Alarcón, E. 2009: "Death and everyday life. The Argaric societies from Southeast Iberia”. Journal of Social Archaeology 9(2): 139-162.

Arribas, A. y Ferrer, J. E. 1997: La necrópolis megalítica del pantano de los Bermejales. Monográfica de Arte y Arqueología 39, Universidad de Granada. Granada.

Arribas, A.; Molina, F.; Torre, F. de la; Nájera, T. y Sáez, L. 1978: "El poblado de la Edad del Cobre de "El Malagón" (Cullar-Baza, Granada)". Cuadernos de Prehistoria de la Universidad de Granada 3: 67-116.

Arteaga, O. 2001: “La Sociedad Clasista Inicial y el origen del Estado en el territorio de El Argar". Revista Atlántico-mediterránea de Prehistoria y Arqueología social 3: 121-219.

Bartelheim, M. 2012: "Detenting Social Structures in the Bronce Age of Southeastern Spain". En T. L. Kienlin y A. Zimmermann (eds.): Beyond Elites. Alternatives to Hierarchical Systems in Modelling Social Formations. Dr. Rudolf Habelt GmbH. Bonn: 339-54.
Bartelheim, M.; Contreras Cortés, F.; Moreno Onorato, A.; Murillo-Barroso, M. y Pernicka, E. 2012. "The silver of the South Iberian El Argar Culture: A first look into production and distribution". Trabajos de Prehistoria 69 (2): 293-309.

Bronk Ramsey, C. 2009: "Bayesian Analysis of radiocarbon dates". Radiocarbon 51(1): 337-360.

Cámara Serrano, J. A. y Molina González, F. 2011: "Jerarquización social en el mundo argárico (2000$1300 \mathrm{aC})$ ". Quaderns de Prehistoria i Arqueología de Castellò 29: 77-100.

Carrasco, J.; Pachón, J. A.; Adroher, A. y López, A. 2002: "Taller metalúrgico de fines del bronce en Guadix (Granada): contribución a la contextualización de las fíbulas de codo tipo Huelva en Andalucía Oriental". Flotentia Iliberritana 13: 357-385.

Castro, P. V.; Chapman, R. W.; Gili, S.; Lull, V.; Mico, R.; Rihuete, C.; Risch, R. y Sanahuja, M. E. 1999: Proyecto Gatas 2. La dinámica arqueoecológica de la ocupación prehistórica. Consejería de Cultura de la Junta de Andalucía. Sevilla.

Castro, P. V.; Gili, S.; Lull, V.; Mico, R.; Rihuete, C.; Risch, R. y Sanahuja, M.E. 1998: "Teoría de la producción de la vida social: mecanismos de explotación en el sudeste ibérico". Boletín de Antropología Americana 33: 25-77.

Chapman, R. 1977: "Burial practices: an area of mutual interest". En M. Springgs (ed.): Archaeology and Anthropology: areas of mutual interest. British Archaeological Reports, Supplementary Series 19. Archaeopress. Oxford: 19-33.

Chapman, R. 1978: "The evidence for prehistoric water control in south-east Spain". Journal of Arid Evironments 1: 261-74.

Chapman, R. 1981: "Archaeological theory and communal burial in Prehistoric Europe". En I. Hodder, G. Isaac y N. Hammond (eds.): Patterns of the past. Studies in honour of David Clarke. Cambrige University Press. Cambrige: 387-411.

Chapman, R. 1991: La formación de las sociedades complejas. El sureste de la península ibérica en el marco del Mediterráneo Occidental. Crítica. Barcelona.

Chapman, R. 2003: Archaeologies of complexity. Routledge. Lonodon.

Chapman, R. 2008: "Producing Inequalities: Regional Sequences in Later Prehistoric Southern Spain". Journal of World Prehistory 21: 195-260.

Childe, V.G. 1936: Man make himself. Watts y Co. London.

Clastres, P. 2010: La sociedad contra el Estado. Virus Editorial. Barcelona. $1^{\text {a }}$ ed. 1974.

Contreras, F. (ed.) 2000: Proyecto Peñalosa. Análisis histórico de la comunidades de la Edad del Bronce del piedemonte meridional de sierra Morena y depresión Linares-Bailén. Arqueología. Monografías 10, Consejería de Cultura de la Junta de Andalucía. Sevilla. 
Contreras, F. y Cámara, J.A. 2002: La jerarquización en la Edad del Bronce del Alto Guadalquivir (España). El poblado de Peñalosa (Baños de la Encina, Jaén). British Archaeological Reports. International Series 1025, Archaeopress. Oxford.

Cruz Berrocal, M.; García Sanjuán, L. y Gilman, A. (eds.) 2013: The Prehistory of Iberia. Debating Early Social Stratification and the State. Routledge. New Yok.

Delibes de Castro, G. 2004: "La impronta Cogotas I en los dólmenes del Occidente de la cuenca del Duero o el mensaje megalítico renovado". Mainake XXVI: 211-31.

Díaz del Río, P. 2004: "Factionalism and collective labor in Copper Age Iberia". Trabajos de Prehistoria 61(2): 85-96.

Díaz del Río, P. 2008: "El contexto social de las agregaciones de población durante el Calcolítico Peninsular". Era-arqueología 8: 128-137.

Díaz del Río, P. 2011: "Labor in the Making of Iberian Copper Age Lineages". En K. Lillios (ed.): Comparative Archaeologies. The American Southwest (AD 900-1600) and the Iberian Peninsula (3000-1500 $B C)$. Oxbow Books. Oxford and Oakville: 37-56.

Dietler, M. 2001: "Theorizing the Feast: Ritual of Consumption, Commensal Politics, and Power in African Contexts". En M. Dietler y B. Hayden (eds.): Feasts. Archaeological and Ethnographic Perspectives on Food, Politics, and Power. Smithsonian Institution Press. London: 65-114.

Fried, M. 1967: The evolution of political society. Random House. New York.

García Sanjuán, L. 2005: "Las piedras de la memoria. La permanencia del megalitismo en el suroeste de la Península Ibérica durante el II y I milenios ANE". Trabajos de Prehistoria 62 (1): 85-109.

García Sanjuán, L. 2011: "Transformations, Invocations, Echoes, Resistance: The Assimilation of the Past in Southern Iberian Monumental Landscapes (V to I millennia BC)". En K. Lillios (ed.): Comparative Archaeologies. The American Southwest (AD 900-1600) and the Iberian Peninsula (3000-1500 $B C$ ). Oxbow Books. Oxford and Oakville: 81-102.

Gilman, A. 1976: "Bronze Age dynamics in southeast Spain". Dialectical Anthropology 1: 307-319.

Gilman, A. 1981: "The Development of Social Stratification in Bronze Age Europe". Current Anthropology 22(1): 1-23.

Gilman, A. 1987: "Unequal development in Copper Age Iberia". En E. M. Brumfiel y T. Earle (eds.): Specialization, Exchange and complex societies. Cambridge University Press. Cambridge: 22-29.

Gilman, A. 2001: "Assessing political development in Copper and Bronze Age Southeast Spain". En J. Hass (ed.): From leaders to rulers. Kluwer Academic/Plenum Publishers. New York: 59-84.

Gilman, A. 2013: "Were There States during Later Prehistory of Southeastern Iberia?" En M. Cruz Be- rrocal, L. García Sanjuán y A. Gilman (eds.): The Prehistory of Iberia. Debating Early Social Stratification and the State. Routledge. New York: 10-28.

Gosden, C. 1999: Anthropology and Archaeology: A Changing Relationship. Routledge. London.

Gosden, C. 2001: "Postcolonial Archaeology: Issues of Culture, Identity, and Knowledge". En I. Hodder (ed.): Archaeological Theory Today. Polity Press. Cambridge: 241-261.

Gosden, C. 2004: Archaeology and Colonialism: Cultural Contacts from 5000 BC to the Present. Cambridge University Press. Cambridge.

Hayden, B. 2001: "Fabulous Feasts. A Prolegomenon to the Importance of Feasting". En M. Dietler y B. Hayden (eds.): Feasts. Archaeological and Ethnographic Perspectives on Food, Politics, and Power. Smithsonian Institution Press. Washington and London: 23-64.

Hayden, B. 2009: "Funerals as Feast: Why Are They so Important?" Cambridge Archaeological Journal 19(1): 29-52.

Hernández Pérez, M. 2012: “El Cabezo Redondo (Villena, Alicante) y el Bronce Tardío en la tierras meridionales valencianas". En J. A. Rodríguez Marcos y J. Fernández Manzano (eds.): Cogotas I. Una cultura de la Edad del Bronce en la Península Ibérica. Universidad de Valladolid. Valladolid: 111-146.

Hernando Gonzalo, A. 2002: Arqueología de la identidad. Akal. Madrid.

Hernando Gonzalo, A. 2012: La fantasia de la individualidad. Sobre la contrucción sociohistórica del sujeto moderno. Katz Editores. Madrid.

Holtorf, C. F. 1997: "Christian landscapes of pagan monuments. A radical constructivist perspective". En G. Nash (ed.): Semiotics of Landscape: Archaeology of Mind (Papers presented at a session of 1994 $T A G)$. British Archaeological Reports, International Series S661, Archaeopress. Oxford: 80-88.

Holtorf, C. 1998: "The life-histories of megaliths in Mecklenburg-Vorpommern (Germany)". En R. Bradley y H. Williams (eds.): The Past in the Past. The Reuse of Ancient Monuments. World Archaeology 30(1): 23-39.

Jover Maestre, F. J. y López Padilla, J. A. 1995: “El Argar y el Bronce Valenciano. Reflexiones en torno al mundo funerario". Trabajos de Prehistoria 52 (1): 71-86.

Jover Maestre, F. J. y López Padilla, J. A. 1999: “Una nueva propuesta de alcance espacial septentrional de las prácticas sociales argáricas". XXIV Congreso Nacional de Arqueología (Cartagena 1997): 275-86. Murcia.

Kalb, P. H. 1994: "Reflexoes sobre utilizaçao de necrópoles megalíticas na Idade do Bronze". $O$ megalitismo no Centro de Portugal. Actas do Seminario (Mangualde 1992). Estudios Pré-Históricos II. 415-26. Viseu.

Leisner, G. y Leisner, V. 1943: Die Megalithgraber der Iberischen Halbinsel: Der Suden. Walter de Gruyter. Berlin. 
Lomba Maurandi, J. 1998: "II Campaña de excavaciones arqueológicas en el yacimiento de "La Serrecica" (Totana, Murcia). 1992". Memorias de Arqueología 7: 60-76.

Lorrio Alvarado, A. J. 2008: Qurénima. El Bronce Final del Sureste de la Península Ibérica. Bibliotheca Archaeologica Hispana 27, Anejo a la Revista Lucentum 17, Real Academia de la Historia, Universidad de Alicante. Madrid.

Lorrio Alvarado, A. J. 2011: "Las sepulturas almerienses del Bronce Final excavadas por Luis Siret". En J. A. Cano García (ed.): Almería, un museo a cielo abierto. La importancia de nuestra provincia en la historia de la Arqueología. Instituto de Estudios Almerienses. Almería: 37-76.

Lorrio Alvarado, A. J. y Montero Ruiz, I. 2004: "Reutilización de sepulcros colectivos en el sureste de la Península Ibérica: la colección Siret". Trabajos de Prehistoria 61(1): 99-116.

Lorrio Alvarado, A. J. y Montero Ruiz, I. 2008: “Dataciones de C-14 de las sepulturas de la Colección Siret estudiadas". En A. J. Lorrio (ed.): Qurénima. El Bronce Final del Sureste de la Península Ibérica. Bibliotheca Archaeologica Hispana 27, Anejo a la Revista Lucentum 17, Real Academia de la Historia, Universidad de Alicante. Madrid: 537-538.

Lull, V. 1983: La cultura del Argar. Un modelo para el estudio de las formaciones sociales prehistóricas. Crítica. Barcelona.

Lull, V.; Micó, R.; Rihuete Herrada, C. y Risch, R. 2010: "Metal and Social Relations of Production in the $3^{\text {rd }}$ and $2^{\text {nd }}$ Millennia BCE in the Southeast of the Iberian Peninsula". Trabajos de Prehistoria 67 (2): 323-347.

Lull, V.; Micó, R.; Rihuete Herrada, C. y Risch, R. 2011: "The Argar and the Biginning of Class Society in the Wetern Mediterranean" En S. Hansen y J. Müller (eds.): Sozialarchäologische Perspektiven: Gesellschaftlicher Wandel 5000-1500 v. Chr. Zwischen Atlantik und Kaukasus. Deutsche Archäeologisches Institut-Von Zabern. Berlin: 381-414.

Lull, V.; Micó, R.; Risch, R. y Rihuete, C. 2009: “El Argar: la formación de una sociedad de clases". En M. Hernández Pérez, J. A. Soler Díaz y J. A. López Padilla (eds.): En los confines del Argar. Una cultura de la Edad del Bronce en Alicante. MARQ Museo Arqueológico de Alicante. Alicante: 224-245.

Lull, V. y Risch, R. 1995: "El estado argárico". Verdolay 7: 97-109.

Lydon, J. y Rizvi, U. Z. (eds.) 2010: Handbook of Postcolonial Archaeology. Left Coast Press. California.

Mataloto, R. 2007: "Paisagem, memoria e identidade: tumulaçoes megalíticas no pós-megalitismo altoalentejano". Revista Portuguesa de Arqueologia 10(1): 123-40.

Mathers, C. 1984a: "Beyond the grave: the context and wider implications of mortuary practices in southeast Spain". En T. F. C. Blagg, R. F. J. Jones y S.
J. Keay (eds.): Papers in Iberia Archaeology. British Archaeological Reports, International Series 193, Archaeopress. Oxford: 13-46.

Mathers, C. 1984b: "'Linnear regression', inflation and prestige competition: 2nd millenium transformations in southeast Spain”. En W. Waldren, R. Chapman, J. Lewthwaite y R. C. Kennard (eds.): The Deya Conference of Prehistory. Early settlement in the West Mediterranean Islands and the Peripheral Areas. British Archaeological Reports, International Series, Archaeopress. Oxford: 1167-1196.

Mergelina, C. 1941-42: "La estación arqueológica de Montefrío (Granada) I. Los dólmenes". Boletín del Seminario de Estudios de Arte y Arqueología XII: 33-106.

Miller, D.; Rowlands, M. y Tilley, C. 1989: Domination and Resistance. Unwin Hyman. London.

Molina, F. 1978: "Definición y sistematización del Bronce Tardío y Final en el sureste de la Península Ibérica". Cuadernos de Prehistoria de la Universidad de Granada 3: 159-233.

Montero Ruiz, I. 1993: "Bronze Age Metallurgy in Southeast of Spain". Antiquity 67: 46-57.

Montero Ruiz, I. 1994: El origen de la metalurgia en el Sudeste de la Península Ibérica. Instituto de Estudios Almerienses. Almería.

Montero Ruiz, I. 2008: “Ajuares metálicos y aspectos tecnológicos en la metalurgia del Bronce Final-Hierro en el Sudeste de la Península Ibérica". En A. J. Lorrio (ed.): Qurénima. El Bronce Final del Sureste de la Península Ibérica. Bibliotheca Archaeologica Hispana 27, Anejo a la Revista Lucentum 17, Real Academia de la Historia, Universidad de Alicante. Madrid: 499-516.

Montón-Subías, S. 2007: “Interpreting archaeological continuities: an approach to transversal equality in the Argaric Bronze Age of south-east Iberia". World Archaeology 39(2): 256-62.

Montón-Subías, S. 2010: "Muerte e identidad femenina en el mundo argárico". Trabajos de Prehistoria 67 (1): 119-137.

Murillo Barroso, M. 2013: Producción y consumo de plata. Un análisis comparativo entre la sociedad argárica y los primeros asentamientos orientalizantes en el Sur de la Península Ibérica. Tesis Doctoral. Universidad Granada.

Murillo Barroso, M.; Aranda Jiménez, G. y Montero Ruiz, I. 2014: "Aspectos sociales del cambio tecnológico: nuevos datos para valorar la introducción de la aleación del bronce en las sociedades argáricas". En E. García Alfonso (ed.): Movilidad, contacto y cambio. II Congreso de Prehistoria de Andalucía. (Antequera 2012). 417-427. Sevilla.

Parcero, C. y Criado, F. 2013: "Social Change, Social Resistance: A Long-Term Approach to the Process of Transformation of Social Landscapes in the Northwest Iberian Peninsula". En M. Cruz Berrocal, L. García Sanjuán y A. Gilman (eds.): The Prehistory 
of Iberia. Debating Early Social Stratification and the State. Routledge. New York: 249-266.

Pujante Martínez, A.; Martínez Rodríguez, A.; Madrid Balanza, M. J. y Bellón Aguilera, J. 2003: "Excavación arqueológica de urgencia en el poblado del Bronce Tardío de Murviedro (Lorca)". XII Jornadas de Patrimonio Histórico y Arqueología Regional (Murcia 2002): 27-30. Murcia.

Ramos Millán, A. 1981: "Interpretaciones secuenciales y culturales de la Edad del Cobre en la zona meridional de la península ibérica. La alternativa del materialismo cultural". Cuadernos de Prehistoria de la Universidad de Granada 6: 242-256.

Ramos Millán, A. 2013: "Villages of Wealth and Resistance in Paradise: Millarian and Argaric Chiefdoms in the Iberian Southeast". En M. Cruz Berrocal, L. García Sanjuán y A. Gilman (eds.): The Prehistory of Iberia. Debating Early Social Stratification and the State. Routledge. New York: 74-98.

Reimer, P. J.; Bard, E., Bayliss, A.; Beck, J. W.; Blackwell, P. G.; Bronk Ramsey, C.; Grootes, P. M.; Guilderson, T. P.; Haflidason, H.; Hajdas, I.; HattŽ, C.; Heaton, T. J.; Hoffmann, D. L.; Hogg, A. G.; Hughen, K. A.; Kaiser, K. F.; Kromer, B.; Manning, S. W.; Niu, M.; Reimer, R. W.; Richards, D. A.; Scott, E. M.; Southon, J. R.; Staff, R. A.; Turney, C. S. M. y van der Plicht, J. 2013: "IntCal13 and Marine 13 Radiocarbon Age Calibration Curves 0-50,000 Years cal BP". Radiocarbon 55(4): 1869-1887.

Riquelme Cantal, J. A. 2002: Cueva de las Ventanas. Historia y Arqueología. Ayuntamiento de Piñar. Granada.

Riquelme Cantal, J. A.; Ubric Rabaneda, P.; Delgado Blasco, P. y Esquivel, J. A. 2001: "Seguimiento arqueológico y excavación de urgencia de una sepultura argárica en la Cueva de las Ventanas, Piñar (Granada)". Anuario Arqueológico de Andalucía 1997 III, 328-332.

Risch, R. 2002: Recursos naturales, medios de producción y explotación social. Un análisis económico de la industria lítica de Fuente Álamo (Almería) 22501400 antes de nuestra era. Iberia Archaeologica 3, Verlag Philipp Zabern, Mainz am Rhein.
Ros Sala, M: 1985: "Nuevas aportaciones para el conocimiento de Bronce Final en el complejo arqueológico Parazuelos-Llano de los Ceperos (Ramonete-Lorca, Murcia)". Anales de Prehistoria y Arqueología 1: 117-122.

Sánchez-Romero, M. 2008: “Actividades de mantenimiento, espacios domésticos y relaciones de género en la sociedades de la Prehistoria Reciente". En L. Prados y C. Ruiz (eds.): Arqueología del Género. ler encuentro internacional en la UAM (Madrid 2005): 93-104. Madrid

Sánchez-Romero, M.; Aranda Jiménez, G. y Alarcón García, E. 2007: "Gender and Age Identities in Rituals of Commensality. The Argaric Societies". Treballs d'Arqueologia 13: 69-89.

Scott, J. C. 2003: Los dominados y el arte de la resistencia. Txalaparta. México.

Service, E. 1962: Primitive social organization. Random House. New York.

Siret, E. y Siret, L. 1890. Las primeras edades del metal en el sudeste de España. Resultados obtenidos en las excavaciones hechas por los autores desde 1881 a 1887. Barcelona.

Siret, L. 2001: L’Espagne préhistorique. Consejería de Cultura de la Junta de Andalucía y Arráez Editores. Sevilla. $1^{\text {a }}$ ed. 1891.

Soler, J.M. 1965: El tesoro de Villena. Ministerio de Cultura. Madrid.

Soler, J.M. 1987: Excavaciones en el Cabezo Redondo (Villena, Alicante). Instituto Juan Gil-Albert. Alicante.

Van Dommelen, P. 2008: “Colonialismo: pasado y presente. Perspectivas poscoloniales y arqueológicas de contextos coloniales". En G. Cano y A. Delgado (eds.): De Tartessos a Manila: siete estudios coloniales y poscoloniales. Publicacions de la Universitat de València. Valencia: 51-90.

Van Dommelen, P. 2011: "Postcolonial archaeologies between discourse and practice". World Archaeology 43(1): 1-6.

Vicent García, J. 1998: "La Prehistoria del Modo de Producción Tributario". Hispania 58(3) 200: 823-839. 